\title{
The Kinetics of Fungicide and Herbicide Release from Slow-Release Formulations Prepared from Degradable Poly-3- Hydroxybutyrate
}

\author{
Evgeniy G. Kiselev *a,b and Sergei V. Baranovskiy ${ }^{\mathrm{a}}$ \\ aSiberian Federal University \\ 79 Svobodny, Krasnoyarsk, 660041, Russia \\ ${ }^{b}$ Institute of Biophysics SB RAS \\ 50/50 Akademgorodok, Krasnoyarsk, 660036, Russia
} Received 03.03.2015, received in revised form 30.03.2016, accepted 01.06.2016

Release kinetics of the fungicide tebuconazole and the herbicide metribuzin from polymeric carriers was investigated. Carriers were prepared from poly-3-hydroxybutyrate as granules, films and 3D forms. The main mechanisms of pesticide release were discovered; kinetic constants for the first order model and Higuchi model were calculated.

Keywords: polyhydroxyalkanoates, pesticides, release kinetics, first order model, model Higuchi.

DOI: $10.17516 / 1997-1389-2016-9-2-233-240$.

(c) Siberian Federal University. All rights reserved

* Corresponding author E-mail address: evgeniygek@gmail.com 


\title{
Кинетика выхода препаратов фунгицидного \\ и гербицидного действия \\ из пролонгированных форм, \\ полученных из разрушаемого \\ поли-3-гидроксибутирата
}

\author{
Е.Г. Киселев ${ }^{\mathrm{a}, \boldsymbol{0}}$, С.В. Барановский ${ }^{\mathrm{a}}$ \\ ${ }^{a}$ Сибирский федеральный университет \\ Россия, 660041, Красноярск, пр. Свободныий, 79 \\ ${ }^{6}$ Институт биофизики СО РАН \\ Россия, 660036, Красноярск, Академгородок, 50/50
}

Проведено исследование кинетики оттока препаратов тебуконазола и метрибузина из полимерных носителей, выполненных из поли-3-гидроксибутирата различной формыл: грануль, пленки и 3D-формы. Выявлены основные закономерности оттока, рассчитаны кинетические константы для модели выхода первого порядка и модели Хигучи.

Ключевые слова: полигидроксиалканоаты, пестициды, кинетика высвобождения, модель первого порядка, модель Хигучи.

\section{Введение}

Современные технологии ведения сельского хозяйства сопровождаются интенсивным применением химических веществ, предназначенных для борьбы с вредителями, сорняками и возбудителями болезней. Большая часть этих веществ и продуктов их распада аккумулируется в биологических объектах, загрязняет почвы, водоемы и нарушает равновесие в природных экосистемах (Hansen, 2004).

Большинство современных пестицидов имеют быстрые темпы деградации в окружающей среде. Если пестицид быстро деградирует в среде, то временное окно (время контакта) для борьбы с вредителями может быть небольшим, что становится причиной снижения его эффективности. Для таких препаратов часто используют системы управляемого высвобождения, чтобы создать эффективный период полураспада в окружающей среде, который больше, чем период полураспада исходного пестицида (Cryer, Wilson, 2009).

Системы управляемого высвобождения распространены во многих областях промышленности: пищевой, фармацевтической, целлюлозно-бумажной и сельском хозяйстве. Первые системы управляемого высвобождения лекарственных средств появились в 1960-х годах (Higuchi, 1961). К настоящему времени данные системы получили широкое распространение, что способствовало возникновению множества форм различного дизайна, а также использованию большого количества различных материалов (Blagoeva, Nedev, 2006).

Перспективными материалами для создания таких систем являются биоразлагаемые 
полимеры, в том числе полимеры микробиологического происхождения - полигидроксиалканоаты (ПГА). Эти полимеры могут быть использованы в качестве обволакивателя семян, депонирования удобрений и пестицидов, а также для изготовления разрушаемых пленок, тары, изделий для тепличных хозяйств и др. ПГА не подвержены быстрому химическому гидролизу в водных средах, а разрушаются в результате биологической деградации под воздействием микроорганизмов (Sudesh et al., 2000; Jendrossek, 2001; Volova et al., 2013). В работах нашего коллектива было показано, что включенные в разрушаемую основу из поли-3-гидроксибутирата [ПЗГБ)] пестициды выходят в почву длительное время по мере разрушения носителя (Volova et al., 2008; Volova et al., 2016b; Voinova et al., 2009; Prudnikova et al., 2013).

Высвобождение препаратов относится к процессу, в котором растворенное вещество мигрирует из исходного положения в полимерной системе к внешней поверхности, а затем в окружающую среду (Langer, 1990). Этот процесс зависит от целого комплекса факторов, таких как физико-химические свойства растворенного вещества, структурные характеристики материала-носителя, окружающей среды оттока и возможных взаимодействий между этими факторами. С помощью математического моделирования возможно описание кинетики выхода действующих веществ из полимерной основы для лучшего понимания и выявления механизма этого сложного процесса. В основном математические модели сосредоточены на одной или двух доминирующих движущих силах.

Цель данной работы - оценка кинетики выхода двух пестицидов, гербицида метрибузина (МЕТ) и фунгицида тебуконазола (ТЕБ), из разрушаемых полимерных форм различной геометрии и с различной первоначальной нагрузкой с использованием эмпирических и полуэмпирических моделей.

\section{Материалы и методы}

В качестве полимерной основы использован биоразрушаемый полимер 3-гидроксимасляной кислоты [П(ЗГБ)]. Из сформированных полимерных систем (раствор, порошок) конструировали формы тебуконазола и метрибузина в виде пленок, микрогранул и объемных 3D-форм (таблеток). Для исследований использовали две нагрузки препаратов - 10 и $50 \%$ от массы полимерной основы. Подробно технология изготовления форм и их характеристики опубликованы в работах (Volova et al., 2016a, 2016b).

Экспериментальные формы пестицидов упаковывали в чехлы из мелкоячеистого мельничного газа и заглубляли в почву, находящуюся в пластиковых контейнерах (по 3 образца в каждом контейнере). Контейнеры размещали в термостате при постоянной влажности почвы 50 \% и температуре $21{ }^{\circ} \mathrm{C}$. Длительность эксперимента составила 60 суток.

Выход МЕТ и ТЕБ (Е) определяли в процентах от включенного в полимерную основу по формуле

$\mathrm{E}=\mathrm{M}_{\mathrm{t}} / \mathrm{M}_{\infty} * 100$,

где $\mathrm{M}_{\mathrm{t}} / \mathrm{M}_{\infty}$ - количество препарата, выпущенного за время $\mathrm{t}$.

Детектирование МЕТ и ТЕБ проводили с помощью газовой хроматографии. Подробная методика описана в предыдущих работах (Volova et al., 2016a, b).

Для описания контролируемого высвобождения препаратов при растворении из полимерных матриксов различной формы использовали эмпирические и полуэмпирические модели. 
Модель первого порядка

(First order model)

Используется для описания оттока препаратов, является кинетикой высвобождения первого порядка. Предполагает, что отток зависит только от концентрации препарата.

$\log \mathrm{C}=\log \mathrm{C}_{0}-\mathrm{Kt} / 2,3$

где $\mathrm{C}$ и $\mathrm{C}_{0}$ - концентрация препарата в момент времени $\mathrm{t}$ и исходная концентрация соответственно; К - константа скорости первого порядка; $\mathrm{t}$ - время.

Данная модель может использоваться для описания оттока растворимых веществ из пористых матриксов (Dash et al., 2010).

\section{Модель Хигучи}

Первая модель была предложена Хигучи в 60-х годах. Изначально она создавалась для плоских систем, но впоследствии была расширена до систем различной геометрии и пористости.

$\mathrm{M}_{\mathrm{t}} / \mathrm{M}_{\infty}=\mathrm{Kt}^{1 / 2}$

где $\mathrm{M}_{\mathrm{t}} / \mathrm{M}_{\infty}$ - количество препарата, выпущенного за время $\mathrm{t}$; $\mathrm{t}$ - время; $\mathrm{K}$ - константа растворения Хигучи.

В этой базовой модели введены следующие ограничения:

- концентрация препарата в полимерном носителе намного выше, чем в окружающей среде;

- диффузия препарата происходит только в одном направлении (не учитываются краевые эффекты) и имеет постоянную величину на протяжении всего процесса;

- размер молекул препарата намного меньше размера системы;
- полимерный носитель набух и не растворяется, не деградирует;

- идеальные условия проницаемости носителя при выходе препарата в окружающую среду (Higuchi, 1963).

Данная модель получила широкое распространение в своё время из-за своей простоты, хотя имеет очень много допусков и приближений. Модель получена из псевдоустойчивого состояния и поэтому имеет весьма ограниченное применение. Действительно, точное решение уравнения даётся для тонких пленок толщиной $\delta$ с равномерным распределением начальной концентрации препаратов и постоянной диффузией при идеальном оттоке $\mathrm{M}_{\mathrm{t}} \sim \mathrm{t}^{0.5}$.

\section{Результаты и обсуждение}

Полученные экспериментальные результаты, включающие показатели выхода пестицидов из форм в почву при нагрузке действующими веществами на 10 и $25 \%$, представлены в табл. 1, 2. Наиболее активно происходил выход из форм тебуконазола (ТЕБ). Максимальный выход ТЕБ зафиксирован у гранул и плёночных образцов, от 81,9 \% до 100 \% от депонированного. Минимальный выход ТЕБ характерен для 3D-форм, не более 60 \%. Максимальный выход МЕТ зафиксирован из плёночных образцов до $92 \%$. Выход MET из гранул составил 54,4 и 50 \% для нагрузки 10 и $25 \%$ соответственно.

Профили выхода исследованных препаратов для всех форм характеризуются наличием области интенсивного выхода действующих веществ и области, в которой выход замедляется. Для плёночных образцов характерен наиболее интенсивный выход в первые 30 суток, за это время выход ТЕБ составил 76,3 и 88,93 \% соответственно для нагрузки 10 и 25 \%. Выход МЕТ из плёнок за это же время составил 65,9 и 76,0 \%. Для гранул и 
Таблица 1. Выход пестицидов из разрушаемых полимерных форм в почву при нагрузке 10 \%

\begin{tabular}{|c|c|c|c|c|c|c|}
\hline \multirow{2}{*}{ Время, сут. } & \multicolumn{6}{|c|}{ Выход (Е), \% } \\
\cline { 2 - 7 } & \multicolumn{3}{|c|}{ Тебуконазол } & \multicolumn{3}{c|}{ Метрибузин } \\
\cline { 2 - 7 } & Гранулы & Плёнки & $3 \mathrm{D}$ & Гранулы & Плёнки & $3 \mathrm{D}$ \\
\hline 0 & 0,00 & 0,00 & 0,00 & 0,00 & 0,00 & 0,00 \\
\hline 10 & 14,30 & 52,70 & 32,83 & 24,00 & 20,80 & 4,80 \\
\hline 21 & 39,00 & 67,00 & 33,83 & 26,00 & 42,00 & 5,50 \\
\hline 30 & 50,30 & 76,30 & 39,83 & 28,70 & 65,90 & 6,60 \\
\hline 45 & 61,70 & 87,20 & 45,83 & 42,00 & 80,00 & 7,00 \\
\hline 60 & 93,70 & 100,00 & 51,50 & 54,40 & 92,40 & 7,90 \\
\hline
\end{tabular}

Таблица 2. Выход пестицидов из разрушаемых полимерных форм в почву при нагрузке 25 \%

\begin{tabular}{|c|c|c|c|c|c|c|}
\hline \multirow{2}{*}{ Время, сут. } & \multicolumn{6}{|c|}{ Выход (Е), \% } \\
\cline { 2 - 7 } & \multicolumn{3}{|c|}{ Тебуконазол } & \multicolumn{3}{c|}{ Метрибузин } \\
\cline { 2 - 7 } & Гранулы & Плёнки & $3 \mathrm{D}$ & Гранулы & Плёнки & $3 \mathrm{D}$ \\
\hline 0 & 0,00 & 0,00 & 0,00 & 0,00 & 0,00 & 0,00 \\
\hline 10 & 28,00 & 40,17 & 39,10 & 25,10 & 44,00 & 6,90 \\
\hline 21 & 40,00 & 61,50 & 47,80 & 37,00 & 62,00 & 5,00 \\
\hline 30 & 50,90 & 88,93 & 55,00 & 44,40 & 76,00 & 3,90 \\
\hline 45 & 74,30 & 98,43 & 59,10 & 50,00 & 87,00 & 27,00 \\
\hline 60 & 81,90 & 100,00 & 58,50 & 50,00 & 92,30 & 43,60 \\
\hline
\end{tabular}

3D-форм выход пестицидов к 30 суткам составил от 6,6 до 55,0 \%. Наибольшее значение зафиксировано для ТЕБ при нагрузке $25 \%$, минимальное для МЕТ при нагрузке $10 \%$. Можно предположить, что скорость выхода из пленок будет определяться остаточной концентрацией пестицидов, а не степенью деградации формы. В начале эксперимента, когда концентрация препарата в форме максимальна, скорость максимальна, профиль оттока характеризуется крутым участком. Далее, по мере снижения концентрации пестицидов в форме, скорость оттока снижается и характер профиля становится более пологим.

Для гранул и 3D-форм на профиле выхода характерно наличие плато, которое характеризуется минимальной скоростью оттока пестицида, но далее в результате деградации носителя скорость оттока возрастает и кривая на графике приобретает экстремальный вид. Такую разницу профилей оттока между пленками и остальными формами можно объяснить конструкцией образцов. Для пленок в виду минимальной толщины отток пестицидов происходит с двух поверхностей. Учитывая минимум толщины носителя, можно заключить, что происходит непосредственный контакт пестицидов с окружающей средой, облегчается доступ к воде, содержащейся в почве; пестицид растворяется быстрее, чем происходит деградация носителя.

У гранул и 3D-форм на первом этапе происходит отток пестицидов, адсорбированных на поверхности носителя, затем концентрация на поверхности снижается и дальнейший 
Таблица 3. Основные кинетические константы, характеризующие выход пестицидов из разрушаемых полимерных форм

\begin{tabular}{|c|c|c|c|c|c|c|c|c|}
\hline \multirow{3}{*}{ Нагрузка, \% } & \multicolumn{4}{|c|}{ Тебуконазол } & \multicolumn{4}{|c|}{ Метрибузин } \\
\hline & \multicolumn{2}{|c|}{ Модель Higuchi } & \multicolumn{2}{|c|}{$\begin{array}{c}\text { Отток первого } \\
\text { порядка }\end{array}$} & \multicolumn{2}{|c|}{ Модель Higuchi } & \multicolumn{2}{|c|}{$\begin{array}{c}\text { Отток первого } \\
\text { порядка }\end{array}$} \\
\hline & $\mathrm{K}_{\mathrm{h}}^{1 / 2}$ & $\mathrm{R}^{2}$ & $\mathrm{~K}, \mathrm{ч}^{-1}$ & $\mathrm{R}^{2}$ & $\mathrm{~K}_{\mathrm{h}}^{1 / 2}$ & $\mathrm{R}^{2}$ & $\mathrm{~K}, \mathrm{\Psi}^{-1}$ & $\mathrm{R}^{2}$ \\
\hline \multicolumn{9}{|c|}{ Гранулы } \\
\hline 10 & 1,90 & 0,92 & 0,0009 & 0,88 & 1,37 & 0,87 & 0,0005 & 0,92 \\
\hline 25 & 1,88 & 0,91 & 0,0007 & 0,91 & 1,45 & 0,98 & 0,0005 & 0,96 \\
\hline \multicolumn{9}{|c|}{ Пленки } \\
\hline 10 & 2,49 & 0,98 & 0,0018 & 0,87 & 3,00 & 0,99 & 0,0021 & 0,95 \\
\hline 25 & 2,38 & 0,94 & 0,0032 & 0,96 & 2,63 & 0,95 & 0,0018 & 0,99 \\
\hline \multicolumn{9}{|c|}{$3 \mathrm{D}$} \\
\hline 10 & 2,36 & 0,98 & 0,0005 & 0,85 & 0,14 & 0,97 & 0,00002 & 0,96 \\
\hline 25 & 1,37 & 0,98 & 0,0005 & 0,94 & 1,70 & 0,86 & 0,0002 & 0,89 \\
\hline
\end{tabular}

отток происходит за счёт диффузии пестицидов, оставшихся внутри формы, через поры и дефекты структуры. Дальнейшее увеличение скорости выхода препаратов из формы связано с деградацией носителя, в результате чего снимаются диффузионные ограничения.

Для дальнейшего анализа были рассчитаны кинетические константы для уравнения (2) и (3) (табл. 3). Математическая модель Хигучи предполагает диффузионно-контролируемое высвобождение (Corrigan, 1985). Растворение пестицидов в нашем случае будет зависеть от концентрации пестицидов, их растворимости и природы носителя. Наибольшее значение константы растворения Хигучи $\left(\mathrm{K}_{\mathrm{h}}\right)$ зафиксировано для образцов в форме плёнок для

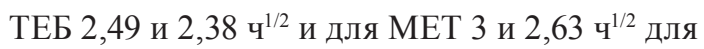
нагрузки 10 и $25 \%$ соответственно. При этом следует отметить, что для МЕТ этот показатель выше, чем для ТЕБ. Это объясняется более высокой растворимостью МЕТ. Значение $\mathrm{K}_{\mathrm{h}}$ указывает на диффузионный механизм растворения. Плёночные образцы согласно модели первого порядка (2) имеют более высокие значения константы скорости растворения (К), - от 0,0018 до 0,0032 ч $^{-1}$.
При рассмотрении кинетики выхода пестицидов из форм в виде гранул и $3 \mathrm{D} \mathrm{K}_{\mathrm{h}}$ и $\mathrm{K}$ снижаются. Снижение константы $\mathrm{K}_{\mathrm{h}}$ связано с возникновением диффузионных затруднений, которые вызваны тем, что часть пестицида находится внутри матрикса-носителя и отделена от почвы слоем гидрофобного полимера. В случае 3D-форм меняется размер носителя и плотность упаковки молекул полимера, полученной контактным прессованием порошка полимера. Так, гранулы, имеющие более рыхлую структуру, характеризуются значениями $\mathrm{K}_{\mathrm{h}}$ от 1,37 до 1,90 ч $^{1 / 2}$, и скорость выхода пестицидов из них составляет от 0,0005 ч$^{-1}$ до 0,0009 ч $^{-1}$. Для 3D-форм $\mathrm{K}_{\mathrm{h}}$ имеет более широкий разброс, - от 0,14 до 2,36 ч$^{-1}$. Можно предположить, что у образца с нагрузкой ТЕБ 10 \% имелись дефекты структуры носителя (микротрещины или сколы), а также, учитывая способ изготовления образцов, всегда имеется вероятность, что распределение пестицидов в структуре носителя не равномерно. Есть вероятность того, что большая часть пестицида будет сконцентрирована внутри носителя, как у 3D-формы, нагруженной на $10 \% \operatorname{MET}\left(\mathrm{K}_{\mathrm{h}}-0,14 \mathrm{u}^{1 / 2} ; \mathrm{K}-0,00002 \mathrm{u}^{-1}\right)$. Так- 
же есть вероятность того, что большая часть пестицида будет сконцентрирована во внешних слоях носителя, о чём может свидетельствовать увеличение значений диффузионной константы и константы скорости растворения у 3D-формы, нагруженной ТЕБ $10 \%$.

Оценка эффективности применяемых моделей определяется коэффициентом детерминации $\mathrm{R}^{2}$. Наилучшая линеаризация экспериментальных данных отмечена для плёночных носителей (модель Хигучи), $\mathrm{R}^{2}$ от 0,94 до 0,98. Модель первого порядка имеет больше отклонений от линейности, это обусловлено непостоянством скоростей оттока и деградацией носителей.

\section{Заключение}

В результате исследований установлено, что матриксы из ПГА могут быть использованы в качестве носителей для препаратов сельскохозяйственного назначения. Выход пестицидов можно регулировать выбором формы носителя. Максимальный выход препаратов зарегистрирован для форм в виде пленок, минимальный - для 3D-форм. 3D-формы можно рассматривать в качестве долгосрочных форм доставки препаратов. Определены основные кинетические характеристики и закономерности выхода препаратов из экспериментальных форм в соответствии с моделью первого порядка и моделью Хигучи. Установлено, что кинетика оттока у разных форм более корректно описывается моделью Хигучи; об этом свидетельствует более высокая линеаризация данных в этой модели и, как следствие, - высокий коэффициент детерминации.

\section{Работа выполнена при поддержске Российского научного фонда по гранту № 14-26- 00039.}

\section{Список литературы}

Blagoeva R., Nedev A. (2006) Monolithic controlled delivery systems: Part II. Basic mathematical models. Bioautomation, 5: 106-117

Corrigan O.I. (1985) Mechanisms of dissolution of fast release solid dispersions. Drug Dev. Ind. Pharm., 11: 697-724

Cryer S.A., Wilson S.L. (2009) Modeling approach to assess clustering impact on release rates of pesticides from microencapsulated products. J. Agricul. Food Chem., 57: 5443-5451

Dash S., Murthy P.N., Nath L., Chowdhury P. (2010) Kinetic modeling on drug release from controlled drug delivery systems. Acta. Pol. Pharm., 67(3): 217-223

Hansen O.C. (2004) Quantitative structure-activity relationships (QSAR) and pesticides. Pesticides Research, 94

Higuchi T. (1963) Mechanism of sustained action medication. Theoretical analysis of rate of release of solid drugs dispersed in solid matrices. J. Pharm. Sci., 52: 1145-1149.

Higuchi T. (1961) Rate of release of medicaments from ointment bases containing drugs in suspensions. J. Pharm. Sci., 50: 874-875

Jendrossek D. (2001) Microbial degradation of polyesters. Adv. Biochem. Eng. Biotechnol., 71: 293-325

Langer R. (1990) New methods of drug delivery. Science, 249: 1527-1533

Prudnikova S.V., Boyandin A.N., Kalacheva G.S., Sinskey A.J. (2013) Degradable polyhydroxyalkanoates as herbicide carriers. J. Polym. Environ., 21: 675-682 
Sudesh K., Abe H., Doi Y. (2000) Synthesis, structure and properties of polyhydroxyalkanoates: biological polyesters. Prog. Polym. Sci., 25: 1503-1555. doi:10.1016/S0079-6700(00)00035-6

Voinova O., Pushkareva E., Volova T. (2009) Environ mentally safe forms of pesticides based on biodegradable polyesters. New Biotechnology, 25: S254

Volova T., Kiselev E., Shishatskaya E., Zhila N., Boyandin A., Syrvacheva D., Vinogradova O., Kalacheva G., Vasiliev A., Peterson I. (2013) Cell growth and accumulation of polyhydroxyalkanoates from $\mathrm{CO}_{2}$ and $\mathrm{H}_{2}$ of a hydrogen-oxidizing bacterium, Cupriavidus eutrophus B-10646. Biores. Technol., 146: 215-222. doi:10.1016/j.biortech.2013.07.070

Volova T., Voinova O., Kalacheva G., Grodnitskaya I. (2008) The prospects of the use of resorbable polyesters for designing safe pesticides. Doklady Biological Sciences, 419: 100-103

Volova T.G., Zhila N.O., Vinogradova O., Nikolaeva E.D., Kiselev E.G., Shumilova A., Shershneva D.A., Shishatskaya E.I. (2016a) Constructing herbicide metribuzin sustained-release formulations based on the natural polymer poly-3-hydroxybutyrate as a degradable matrix. Journal of Hazardous Materials, Part B, 51 (2): 113-125

Volova T., Zhila N., Vinogradova O., Shumilova A., Prudnikova S., Shishatskaya E., (2016b) Characterization of biodegradable poly-3-hydroxybutyrate films and pellets loaded with the fungicide tebuconazole. Environ Sci Pollut Res, 23(6): 5243-5254. DOI: 10.1007/s11356-015-5739-1 